\title{
Effect of Peer Teaching Versus Traditional Teaching Method on Nursing Students' Performance Regarding Pediatric Cardio pulmonary Resuscitation
}

\author{
Amal Gharib sabaq \\ Lecturer of Pediatric Nursing Faculty of Nursing, Benha University
}

\section{Manal Farouk}

Lecturer of Pediatric Nursing, Faculty of Nursing, Suez canal University

\section{Safaa Salah Ismail}

Assistant professor of Pediatric Nursing, Faculty of Nursing, Helwan University

\begin{abstract}
Background: Peer teaching has been used in education to address critical thinking, psychomotor skills, cognitive development, and academic gains. It can be an alternative to traditional instruction by a specialist that enables more students to be trained in CPR. As it is widely available, cost-effective, and culturally attuned. Aim of the current study is to determine the effectiveness of peer teaching on the performance of nursing students' regarding pediatric cardio pulmonary resuscitation. A Quasi-experimental research design was used to conduct the current study at the clinical Pediatric laboratory skills, Faculty of Nursing, Suez canal University. Subjects: All 92 nursing students enrolled in the $3^{\text {rd }}$ year, were agreed to participate in the study. These were divided into two groups equally; study and control groups and was selected randomly. Tools: Four tools were used for data collection: A Structured Interviewing Questionnaire Schedule, Student's Clinical Evaluation checklist, Clinical Teaching Preference Questionnaire and Peer Teaching Experience Questionnaire. Results: The study findings indicate that, the knowledge and performance scores of the nursing students studying by peer teaching method will be significantly better than those studying by traditional teaching methods. The student in this group agreed on many benefits of the peer teaching both as teachers' and student. Conclusion: Based on the results of the present study, it was concluded that, our study findings add more support in favor of the peer teaching approach evidence by an obvious improvement in students' knowledge and performance scores. Moreover, The majority of students in this group feeling less anxious, comfortable, more self confident in teaching as well as improving their communication skills Recommendation: Adopt peer teaching method in undergraduate nursing curricula for teaching clinical skills to enhance students' acquisition of knowledge with better performance. Similar studies should replicate the current study with a larger sample size at several universities in order to provide stronger evidence for generalized the results.
\end{abstract}

\section{Key words}


Peer teaching, Pediatric cardio pulmonary resuscitation, Nursing student, performance, traditional teaching method.

\section{Introduction:}

Cardio pulmonary resuscitation(CPR) is an essential skill for the survival of children after cardiac arrest. It is a one of the important skills in Basic life support and associated with increased chances of survival rate ${ }^{(1)}$ With more student trained in cardio pulmonary resuscitation, more lives can potentially be saved; however, the high cost in terms of time, money, and opportunity of traditional training programs limits the number of student trained to perform cardio pulmonary resuscitation. Therefore, one effective educational approach to this situation is innovative teaching methods such as peer teaching that may be advantageous. At a time when there is pressure to train more nurses and minimize costs, ${ }^{(2)}$ It can be utilized to pass information to large groups of students with less faculty member involvement. Furthmore, peer training in CPR by pairing of nursing students can provide CPR skills of equally good quality as that provided by professional training ${ }^{(3)}$.

A peer is a student of the same age, group, academic level, or experience level. The term "peer" can also refer to student who have equivalent skills of different experiences ${ }^{(4)}$. Also, Peer teaching is described as a two-way reciprocal learning activity which includes sharing knowledge, ideas, and experiences in a way that has some benefits for both groups of peer and student ${ }^{(5)}$. Professional nurses must be able to exercise their multiple roles of care providers, managers, teachers, as well as lifelong learners and researchers (6). To do so, they should be able to solve clinical problems through analysis, synthesis, critical thinking, and effective communication. Such skills are not expected to be provided through traditional teaching, but need an active learning process with peer teaching opportunities $^{(7)}$.

Peer teaching is based on Bandura's social learning theory, which postulates that individuals learn dramatically from observing the behaviors of the others ${ }^{(8)}$. In nursing schools, peer teaching is more used in laboratory settings where students alternatively play the roles of peer teachers and peer learners ${ }^{(9)}$. As peerteachers, students are asked to design teaching plans that include specific, concrete objectives related to a skill or topic, and identify relevant resources, and then apply this to small groups of 
students ${ }^{(10)}$. This prepares the nursing students for their future roles as educators, builds their self esteem, and enhances their psychomotor skills and their attitudes ${ }^{(11)}$.

Neonatal and pediatric resuscitation are the standard of practice for all neonatal and pediatric nursing practitioners. It consists of artificial respiration, cardiac massage and medication. It decides the life of a neonate or a child who is at risk of survival from dependent to independent life ${ }^{(12)}$. Cardiac arrest described as a sudden cessation of cardiac activity, unless action is immediately taken. The lack of circulation leads to irreversible damage to the body's vital organs within minutes ${ }^{(13)}$.

Peer teaching process is designed to benefit both the peer learner and peer teacher by reinforcing and increasing their knowledge and practical skills relating to the topic being taught, feeling more comfortable, less anxious, less isolated, and more confident as well as improving their communication skills. Also, Peer teaching has the potential to provide educational opportunities which may be unachievable by staff or might not be effectively utilized by staff given ever increasing constraints, such as larger class sizes and increased administration duties (14). In spite of these benefits, evidences indicate that in nursing education, there is less attention given to peer teaching over recent years ${ }^{(15)}$. Accordingly, this study conducted to assess the effectiveness of peer teaching on the nursing students' performance regarding pediatric cardio pulmonary resuscitation.

During the last 20 years, there have been different approaches to teaching nurse students CPR. Now, more effective student-centric learning methods are being utilized to encourage active student participation and creative thinking instead of traditional teaching method ${ }^{(16,17)}$. One of these methods is peer teaching that, could utilize resources more effectively with students teaching and supervising more students, thus decreasing the demand on the responsible faculty members ${ }^{(18)}$.

Third year students attend a pediatric nursing course aimed at enabling them to apply pediatric cognitive and motor skills in clinical settings. The course has formal lectures (theory) and clinical sessions (practical). The practical part of pediatric nursing course focuses on learning students how to make cardio pulmonary resuscitation in the skills lab by assistant nursing staff to a group of up to 20 
students, a situation that makes guidance and supervision of the practical performance of each student not feasible. To overcome this and at the same time to motivate students' active learning, the researchers started applying peer teaching methods. The situation provides a kind of natural experiment to compare peer teaching with the traditional clinical session method.

\section{Aim of the Study:}

To determine the effectiveness of peer teaching on the nursing students' performance regarding pediatric cardio pulmonary resuscitation.

\section{Research Hypothesis:}

The performance scores of the nursing students studying by peer teaching method was significantly improve more than those studying by traditional teaching method.

\section{Subjects and Method:}

\section{Research Design:}

A quasi-experimental design was used in the present study.

\section{Setting:}

The study was conducted at the clinical Pediatric laboratory skills for third year students' Faculty of Nursing, Suez canal University.

\section{Sample:}

All 92 nursing students enrolled in the $3^{\text {rd }}$ year, were agreed to participate in the study. These were divided equally into two groups randomly. Group I (study group) consisted of 46 pediatric nursing students studying with peer teaching method and Group II (control group) included the other 47 pediatric nursing students studying with traditional teaching method and who were similarly assigned to the 3 skill labs in subgroups of around 15 students each. The students were allocated to either control or study group by using simple randomization method.

\section{Tools of Data collection:}

Four tools were used to collect data in this study.

\section{Tool I : A Structured Interviewing}

Questionnaire Schedule : It was developed by the researchers after reviewing the related literature of Parajulee and Selvaraj, (2011) ${ }^{(19)}$ to assess the students' knowledge regarding pediatric cardio pulmonary resuscitation . It comprised two main parts:

Part I: Personal characteristics of the studied students which included age, gender and residence.

Part II: Students' knowledge regarding pediatric cardio pulmonary resuscitation. It consisted of 20 true / false and multiple 
choice questions covering the questions related to (definition of CPR, signs and symptoms of cardiac arrest, Component of Advanced cardiac life support, CPR mistakes, complication of CPR, and technique of CPR. .ect).

The scoring system consisted of giving a score of one for the correct answers and zero for the wrong answers. Total scores was range from 0-20.

\section{Tool II : Student's Clinical Evaluation}

Checklist : It was adopted from Wolters \&Kluwer (2011) ${ }^{(20)}$ to evaluate the nursing student's performance toward applying steps of cardio pulmonary resuscitation taught in the practical part of the nursing pediatric course, and applied in the clinical setting. The tool consisted of 12 steps and covered the following items ( Safe approach and position, Infant's responsiveness, Shout for help, Chin lift /head tilt, Look - listen and feel for up to 10 seconds, Clear the airway, Deliver rescue breath, Check brachial pulse, Continue respiration for one minute, Telephone for the team, Check brachial pulse, Commence chest compressions : Correct hand position Correct compression rate - Correct ratio). The score of total performance was 14 (each stage was allocated one point except for stage 12 (commence chest compressions), where three points were allocated due to the complexity of the procedure.). The point grade system of performance in the Faculty of Nursing, Suez canal University, was applied to the total score as follows: Fail $(<60 \%)$, Pass (60 - <65\%), Good (65 - <75\%), Very good $(75-<85 \%)$, and Excellent $(>85 \%)$.

Tool III: Clinical Teaching Preference Questionnaire (CTPQ): It was adopted from Iwasiw \& Goldenberg, (1993) ${ }^{(21)}$ to assess nursing student's preference of peer teaching method. It consists of 10 statements ( I can communicate more freely with my peers than with my instructor, I am less anxious when performing a nursing skill in the presence of my peers than in the presence of my instructor, and I am more self-confident examples of items) with a five-point Likert scale ranging from "strongly agree" to "strongly disagree." The responses were dichotomized into two categories: "strongly agree/agree" and "strongly disagree/disagree/uncertain".

Tool IV: Peer Teaching Experience Questionnaire (PTEQ): It was adopted from Iwasiw \& Goldenberg, (1993) ${ }^{(21)}$ to assess nursing student's experience gained from practice of peer teaching method. It consists of 14 statements (I now understand the principles underpinning 
teaching and learning, I felt comfortable teaching the other students, Teaching is an important role for nurses, \& I would be more confident teaching a clinical skill examples of items) with similar scoring as the Clinical Teaching Preference Questionnaire.

\section{Validity and reliability of study tools:}

Before data collection, face and content validity of the tools through rigorous review by a panel of experts in pediatric nursing department. The panel consisted of 5 Faculty members from the Faculties of Nursing at Zagazig and Ain shams universities. Modifications of the tools were done according to the expert's judgment on clarity of sentences, appropriateness of content and sequence of items. The experts' agreed on the content . Internal consistency reliability of all items of the tools were assessed using coefficient alpha. It was 0.79 for a structured interviewing questionnaire schedule, 0.84 for Student's Clinical Evaluation Checklist, 0.86 for Clinical Teaching Preference Questionnaire, and 0.87 for peer teaching experience questionnaire.

A pilot study was carried out with $10.0 \%$ of the total sample size (approximately 9 nursing students) over a period of one month (August, 2014). The purpose was to ascertain the feasibility of the study and the clarity and applicability of the tools. It also helped to estimate the time needed for filling out the forms. Based on the results of the pilot, no modifications were needed and pilot study subjects were excluded from the sample of the study.

Ethical Considerations: The researchers obtained the official permissions to conduct the study from the Dean of the Faculty Nursing, Suez canal University. An individual informed consent was obtained from each student after full explanation of the study objectives and procedures. Students were reassured that participation is totally voluntary, that refusals or withdrawals have no consequences, and that the information would be strictly confidential and does not affect the assessment of their academic achievement.

\section{Field Work:}

After allocation of the students to the study (peer teaching method) and control(traditional teaching method) groups, initial assessment of students' knowledge regarding pediatric cardio pulmonary resuscitation was carried out for both groups using tool I. Then, the researchers conducted a one-day workshop starting the teaching sessions. The attendants were the assistant teaching 
staff assigned to the clinical sessions and the nursing students in the study group. It was for orientation the participants regarding peer teaching benefits, techniques and tutor role.

The researchers select the pediatric cardio pulmonary resuscitation skill that nursing students must learn in the clinical part of the nursing pediatric course. This content was similar in both study and control groups.

The study group (46) students were assigned to (three) skill labs in subgroups of around (15) students each. The subgroup in each lab was further subdivided into three small groups (one peer teacher\& four students in each group) for implementation of the peer teaching process.

Each student was allowed to perform the steps of pediatric cardio pulmonary resuscitation on infant manikin in the Faculty skill lab of pediatric under the supervision of researchers. This was repeated until the student mastered this skill. The student then designed a teaching plan that includes specific objectives, and identified the resources relevant to peer teaching. The researchers prepared a schedule for the trained students to act as peer teachers for their other colleagues regarding pediatric cardio pulmonary resuscitation.

The control group (46) students were sub grouped and distributed to 3 skill labs. These subgroups were trained by assistant teaching staff in traditional clinical sessions.

The clinical sessions started from 9 AM to $11 \mathrm{AM}$ for the study group and from 11.30 AM to 1.30 PM for control group three day/week for 21days.

The evaluation of the effect of peer teaching was carried out through the use of the first and second tools and comparing its results among students in the study and control groups after the end of the clinical sessions. Additionally, the study group students' preference and experience regarding the peer teaching method was assessed using the third and fourth tools (CTPQ \& PTEQ). The collection of data lasted two months starting from September to October 2014.

\section{Data analysis:}

The collected data revised, organized, tabulated and analyzed by using SPSS version 20. Numerical data was presented in tables by using Mean, Standard deviation .Qualitative variables were described as frequency and percentage and compared using Chi square test $\left(\mathrm{X}^{2}\right)$ as the test of significance. Independent $(\mathrm{t})$ 
test was used to compare mean score between two groups. A significant level value was considered when $\mathrm{p}$-value $\leq$ 0.05 and a highly significant level value was considered when p-value $\leq 0.001$, while p-value > 0.05 indicates nonsignificant results.

\section{Results:}

Table (1) shows the percentage distribution of the studied students according to personal characteristics. It was observed that more than two thirds of students $(65.2 \%)$ in the control group were aged 20 to less than 21years old compared to $50.0 \%$ in the study group with a mean age $20.98 \pm 2.14$ and $20.45 \pm 2.07$ years in the control and study groups respectively. Regarding gender of students, majority of them were females $78.3 \%$ in the study group and $69.6 \%$ in the control group. The table also, illustrates that two thirds of students $(60.9 \%)$ in the study group came from urban areas compared with $32.6 \%$ in the control group.

Table (2) shows the mean scores of students' total knowledge regarding cardio pulmonary resuscitation. It was observed that, the mean scores of students' total knowledge regarding cardio pulmonary resuscitation afterteaching were $11.6 \pm 0.639$ and $9.6 \pm$
0.814 in the study and control groups respectively with statistically significant difference ( $\mathrm{p}$-value <0.001). The table also reveals that, there was no significant difference in the mean scores of students' total knowledge regarding cardio pulmonary resuscitation in the study and control groups before-teaching ( $p$-value $>0.05$ ).

Table (3) shows the mean scores of students' total performance regarding cardio pulmonary resuscitation. It was observed that, the mean scores of students' total performance regarding cardio pulmonary resuscitation afterteaching were $11.6 \pm 0.639$ and $9.6 \pm$ 0.814 in the study and control groups respectively with statistically significant difference ( $p$-value 0.001).

Table (4) Shows percentages of performance grades of nursing students in the study and control groups. It was revealed from the table that there was a statistically significant differences in the total performance grades between the students in the study and in the control groups $(\mathrm{p}<0.0001)$. Overall, the highest percentage of the study group (71.7\%) have excellent grade, compared to only $15.2 \%$ of those in the control group 
Concerning study group students' feedback regarding their preferences of the peer teaching

method, Table (5) shows that more than two third $69.5 \%$ of them agreed upon the issues related to better acquisition of problem solving skills, increase sense of responsibility, more interactive and collaborative with others students, received honest feedback, more self confidence, less anxious, better communication and helping in general.

As for the study group students' opinion about the experiences gained from their practice of peer-teaching. Table (6) illustrates that the highest agreement is upon feeling more comfortable and confident in teaching a clinical skill for students $(76.1 \%$ \& $76.1 \%)$ respectively, followed by improving their ability to understand the principles underpinning teaching and learning as well as peer teaching experience was personally rewarding $(73.9 \% \& 73.9 \%)$ respectively. On the other hand, the majority $69.5 \%$ of the students believed that peer teaching experience was time and effort spent. However, only $10.9 \%$ \& $8.7 \%$ of the students agreed that the teaching is an important role for nurses and that they have a professional responsibility to teach students and their peers respectively.

Table (1): Distribution of the Students According to their Personal Characteristics (N=92).

\begin{tabular}{|c|c|c|c|c||}
\hline \multirow{2}{*}{$\begin{array}{c}\text { Personal } \\
\text { Characteristics }\end{array}$} & \multicolumn{2}{|c|}{$\begin{array}{c}\text { Control group } \\
\text { N=46 }\end{array}$} & \multicolumn{2}{c||}{ N=46 } \\
\cline { 2 - 5 } & No & $\%$ & No & $\%$ \\
\hline Age in years & 23 & 50.0 & 30 & 65.2 \\
\hline $20<$ & 20 & 43.8 & 10 & 21.7 \\
\hline $21<$ & 3 & 6.2 & 6 & 13.1 \\
\hline $22>$ & $20.45 \pm 2.07$ & & $20.98 \pm 2.14$ \\
\hline Mean \pm SD & 10 & 21.7 & 14 & 30.4 \\
\hline Gender: & 36 & 78.3 & 32 & 69.6 \\
\hline Male & \multicolumn{3}{|c|}{} \\
\hline Female &
\end{tabular}




\begin{tabular}{|c|c|c|c|c|}
\hline \multicolumn{5}{|l||}{ R Residence } \\
\hline Urban & 28 & 60.9 & 15 & 32.6 \\
\hline Rural & 18 & 39.1 & 31 & 67.4 \\
\hline
\end{tabular}

Table (2) Total Mean Scores of Students' knowledge regarding Cardio-Pulmonary Resuscitation $(\mathrm{N}=92)$.

\begin{tabular}{|c|c|c|c|c|}
\hline \multirow{2}{*}{ Assessment time } & $\begin{array}{l}\text { Study group } \\
\qquad \begin{array}{l}\mathrm{N}=46 \\
\end{array}\end{array}$ & $\begin{array}{l}\text { control group } \\
\qquad \mathrm{N}=46\end{array}$ & $\begin{array}{c}\text { Independent } \\
\text { t test }\end{array}$ & $P$ value \\
\hline & $\begin{array}{rr}\text { Mean } & \pm \\
\text { SD } & \end{array}$ & $\begin{array}{l}\text { Mean } \pm \\
\text { SD }\end{array}$ & & \\
\hline Before- teaching & $5.21 \pm 4.28$ & $5.09 \pm 3.98$ & 0.398 & $>0.05$ \\
\hline After-teaching & $11.6 \pm 0.639$ & $9.6 \pm 0.814$ & 4.495 & $<0.001 * *$ \\
\hline
\end{tabular}

Table (3) Total Mean Scores of Students' Performance regarding Cardio-Pulmonary Resuscitation $(\mathrm{N}=92)$.

\begin{tabular}{|c|c|c|c|c|}
\hline \multirow{2}{*}{ Assessment time } & $\begin{array}{l}\text { Study group } \\
\qquad \mathrm{N}=46\end{array}$ & $\begin{array}{l}\begin{array}{c}\text { control } \\
\text { group }\end{array} \\
\mathrm{N}=46\end{array}$ & \multirow[t]{2}{*}{$\begin{array}{c}\text { Independent } \\
\text { t test }\end{array}$} & \multirow[t]{2}{*}{$P$ value } \\
\hline & $\begin{aligned} \text { Mean } & \pm \\
\text { SD } & \end{aligned}$ & $\begin{array}{l}\text { Mean } \pm \\
\text { SD }\end{array}$ & & \\
\hline After-teaching & $11.6 \pm 0.639$ & $9.6 \pm 0.814$ & 4.495 & $<0.001 * *$ \\
\hline
\end{tabular}

Table (4) Percentages of Performance Grades of Nursing Students in the Study and Control Groups $(\mathrm{N}=92)$

\begin{tabular}{|l|c|c|c|c|c|c|}
\hline \multirow{2}{*}{ Performance grades } & \multicolumn{2}{|c|}{$\begin{array}{c}\text { Study group } \\
(\mathbf{N}=\mathbf{4 6})\end{array}$} & \multicolumn{2}{c|}{$\begin{array}{c}\text { Control group } \\
(\mathbf{N}=\mathbf{4 6})\end{array}$} & \multirow{2}{*}{ X2 Test } & \multirow{2}{*}{ P-value } \\
\cline { 2 - 5 } & $\mathbf{N o}$ & $\mathbf{\%}$ & $\mathbf{N o}$ & $\mathbf{\%}$ & & \\
\hline Poor & 0 & 0.0 & 16 & 34.8 & & \\
\cline { 1 - 5 } Good & 5 & 10.9 & 14 & 30.4 & \multirow{2}{*}{54.051} & \multirow{2}{*}{$0.0001^{* *}$} \\
\hline Very good & 8 & 17.4 & 9 & 19.6 & & \\
\hline
\end{tabular}




\begin{tabular}{|l|l|l|l|l|l|l|}
\hline & & & & & & \\
\cline { 1 - 5 } Excellent & 33 & 71.7 & 7 & 15.2 & & \\
\hline
\end{tabular}

Table (5): Agreement upon Peer teaching preferences among nursing students in the study group $(\mathrm{No}=46)$

\begin{tabular}{|c|c|c|}
\hline Statement & & $\begin{array}{l}\text { gly } \\
\text { igree }\end{array}$ \\
\hline & No & $\%$ \\
\hline $\begin{array}{l}\text { 1-My ability to problem solving improves less from instructor teaching } \\
\text { than from my peers }\end{array}$ & 32 & 69.5 \\
\hline $\begin{array}{l}\text { 2-Being taught clinical skills by my instructor decreases my sense of } \\
\text { responsibility more than being taught by my peers }\end{array}$ & 32 & 69.5 \\
\hline 3-I learn less from my instructor than my peers & 31 & 67.4 \\
\hline $\begin{array}{l}\text { 4-I do not feel freer to approach my instructor for help than I do my } \\
\text { peers }\end{array}$ & 30 & 65.2 \\
\hline $\begin{array}{l}\text { 5-Being taught clinical skills by my peers increases my interaction and } \\
\text { collaboration with other students more than being taught by my }\end{array}$ & 32 & 69.5 \\
\hline instructor & 32 & 69.5 \\
\hline $\begin{array}{l}\text { 6-The feedback I receive from my peers, is from a student's viewpoint, } \\
\text { therefore, more honest, reliable, helpful than from my instructor }\end{array}$ & 32 & 69.5 \\
\hline $\begin{array}{l}\text { 7-I am more self-confident and able to perform independently because } \\
\text { of being taught by my peers, more than by my instructor }\end{array}$ & 32 & 69.5 \\
\hline $\begin{array}{l}\text { 8-I am less anxious when performing a nursing skill in the presence of } \\
\text { my peers than in the presence of my instructor }\end{array}$ & 32 & 69.5 \\
\hline $\begin{array}{l}\text { 9-I can communicate more freely with my peers than with my instructor } \\
\text { 10-My peers are more supportive to me when I am performing a } \\
\text { nursing skill than my instructor. }\end{array}$ & 28 & 60.9 \\
\hline
\end{tabular}

Table (6): Agreement upon the Experience Gained from Peer Teaching among Students in the Study Group ( $N=46)$

\begin{tabular}{|l|c|c|}
\hline \multicolumn{1}{|c|}{ Statement } & \multicolumn{2}{c|}{$\begin{array}{c}\text { Strongly } \\
\text { agree/ agree }\end{array}$} \\
\cline { 2 - 3 } & No & \% \\
\hline 1- I felt uncomfortable assessing the other students' skills & 28 & 60.9 \\
2- The peer teaching experience was time and effort well spent & 32 & 69.5 \\
3- I now understand the principles underpinning teaching and learning & 34 & 73.9 \\
4- I have developed skills for teaching basic clinical skills & 31 & 67.4 \\
5- I felt comfortable teaching the other students & 35 & 76.1 \\
6- I was initially apprehensive about the peer teaching requirement in the & 32 & 69.6 \\
clinical session & & \\
7- The peer teaching experience allowed me to reflect on my own & 30 & 65.2 \\
previous learning & & \\
8- There should be more opportunities or peer teaching in the curriculum & 32 & 69.6 \\
9- I enjoyed working with the other students & 31 & 67.4 \\
10- The peer teaching experience was personally rewarding & 34 & 73.9 \\
11- Nurses have a professional responsibility to teach students and their & 4 & 8.7 \\
peers & 7 & 15.2 \\
12- What I have learnt in this experience will help with my graduate & 35 & 76.1 \\
\hline
\end{tabular}




\begin{tabular}{|l|l|l|}
\hline nurse role & 5 & 10.9 \\
13- I would be more confident teaching a clinical skill after this \\
experience \\
14- Teaching is an important role for nurses
\end{tabular}

groups were similar. This result is in

\section{Discussion:}

Peer teaching has been used in education to address critical thinking, psychomotor skills, cognitive development, and academic gains ${ }^{(22)}$. It can be an alternative to traditional instruction by a specialist that enables more students to be trained in CPR . As it is widely available, costeffective, and culturally attuned. Peer teaching has significant positive effects on educational achievement by offering relationships that provide encouragement and companionship. Thus, it is suitable for students and may enable them to reach a skill level in CPR similar to the level reached by those trained by healthcare providers ${ }^{(23)}$.

The aim of the current research is to determine the effectiveness of peer teaching on performance of nursing students regarding pediatric cardio pulmonary resuscitation. This aim was achieved throughout the study findings and the research hypothesis was accepted.

Regarding personal characteristics data of the studied third year pediatric nursing students in relation to age, the present study revealed that the mean age of both agreement with the study of Fujiwara etal., ( 2011) ${ }^{(24)}$ who conducted a study to compare peer-led versus professional-led

training in basic life support for medical students and revealed that the mean age of the participants were similar between the study and control groups. Furthermore, the majority of students in the study and control groups were females. This might be due to the greater fraction of the nurses in Egypt was female and may also related to the studying of nursing in the Egyptian Universities was exclusive for females only till ten years ago.

The current study figured out that there was a significant increase in students' total knowledge about CPR after studying by peer teaching method. This may be due to the use of peer teaching method that contributed to an increase learning curve and acquisition of knowledge than would have occurred if students were studying with traditional method. The study result is consistent with Burgess \& Nestel, (2014) (25) who postulated that peer teaching increased theoretical knowledge acquisition for learner. Again, Stone, (2013) (26) founded that, there was an 
improvement in nursing students' knowledge after studying by peer teaching method. Contradicts with study from Cho etal., (2015) ${ }^{(27)}$ who revealed that, there was no significant differences in knowledge about CPR of the two groups of nursing students exposed to peer and traditional teaching methods.

The findings of the current study indicate that there is an obvious improvement in performance scores among peer teaching group. Moreover, majority of nursing students in this group got a total "excellent" grade, compared to few ones in the control group. The findings go in line with a number of previous studies of Graziano, (2011) ${ }^{(28)}$; Schauseil-Zipf etal., (2010) ${ }^{(29)}$ who founded that, the performance scores of students studying by peer teaching method were better than those studying by traditional method. On the same line, Christiansen etal., (2011) (30) found that, peer teaching was more effective educational tool than traditional methods in enhancing the practical skills of students and supporting each other.

Nevertheless, the success of peer teaching approach in the present study, is related to the process of the application of the intervention and the facilities provided for achieving its goals, may be the clear explanations provided by the researchers for students to foster their peer teaching abilities, in addition to training them in mastering the selected practical skill until they became competent before starting the sessions, and teaching them how to prepare for teaching session.

Our findings add more support in favor of the peer teaching approach and may be taken in consideration as an educational tool in pediatric cardio pulmonary resuscitation training for nursing students. This result is in agreement with Cho etal., (2015) ${ }^{(27)}$ who showed that, peer teaching may be an effective method for training students to perform CPR . Similarly, Williams etal., (2014) ${ }^{(31)}$ who concluded that, peer teaching could be a useful adjunct in clinical skills training. In contrary, previous study by Hughes etal., (2010) ${ }^{(32)}$ failed to show the supremacy of peers teaching in CPR training compared with traditional approaches.

The findings of the present study indicates that, peer teaching enhanced social interaction and collaboration between peer and student. This may be because the peer teaching provide an opportunity to the student to explore ideas without fear of embarrassing themselves in front of their lecturer. This result came in line with Williams etal., (2014) ${ }^{(31)}$ who revealed that, social interaction and collaboration 
was increased in peer teaching group more than traditional teaching group. At the same line, Cho etal., (2015) ${ }^{(27)}$ reported that, all student in peer teaching group were became social interactive with other students, more friendly, and learned collaboratively.

The most convincing finding from this study was that the students studying by peer teaching expressed their better acquisition of problem solving skills, sense of responsibility, better learning and helping in general. This may be because the student in peer teaching group gives a sense of autonomy when they accepted responsibility for their own education. These results are in congruence with the previously study by Daley etal., (2008) ${ }^{(33)}$ who reported positive effects of peer teaching on students' abilities of problem solving.

Our findings indicate that the majority of nursing students who studying by peer teaching, were less anxious when performing lab skill, more communicative $\&$ and received honest feedback. This may be because the peer teaching help to create cooperative, relaxed learning environment and the student were more confident asking questions, openness to the ideas of others and voicing their opinions than they were previously. These results are in accordance with the previously reported in other studies of Harmer etal., (2011) ${ }^{(34)}$; Mckenna \& French,(2011) ${ }^{(15)}$; Rush etal., (2012) ${ }^{(35)}$ found that the majority of students studying by peer teaching expressed their less anxiety, improved communication skills and received honest feedback.

On the other hand, this finding disagreement with the previously study by Brannagan etal., (2012) ${ }^{(36)}$ who reported that, students receiving peer tutoring were statistically more anxious about performing lab skills and some students found instructors' feedback more helpful than their peers.

The present findings demonstrated that, most of the students found the experience of peer teaching were comfortable and more self confident in teaching clinical skills, as well as understanding the principles underpinning teaching and learning. These result are in agreement with the previously studies of Bensfield etal., (2008) ${ }^{(37)}$; Weyrich etal., (2009) ${ }^{(14)}$ ; Christiansen \& Bell, (2010) ${ }^{(38)}$ reported that, nursing students in peer teaching group were more comfortable and confidence in teaching, as well as improving their ability to understand the principles of teaching and learning. 
Nonetheless, majority of the peer teaching students expressed that peer teaching experience was time and effort spent. Subsequently, only a few of the students believe that the teaching is an important role for nurses and that they have a professional responsibility to teach students and their peers. This might be explained as this was the first time for students to act as teachers, and they might have had the feeling of having a responsibility that was beyond their capabilities. Added to this the student felt unprepared or unwilling to undertake this role. These result are contradicted with the previously study by William etal., (2014) (31) who significantly revealed that, majority of students in peer teaching group got a high mean score regarding teaching is an important role for nurses and recommended the importance of imbedding peer teaching into the curricula for recognizes and formalizes of teaching.

\section{Conclusion:}

Based on the results of the present study, it was concluded that, our study findings add more support in favor of the peer teaching approach evidence by an obvious improvement in students' knowledge and performance scores. Moreover, The majority of students in this group feeling less anxious, comfortable, more self confident in teaching as well as improving their communication skills.

\section{Recommendations:}

In the light of the present study, the following recommendations are suggested:

1. Adopt peer teaching method in undergraduate nursing curricula for teaching clinical skills to enhance students' acquisition of knowledge with better performance.

3. Encourage assistant teaching staff to Consider peer teaching as useful adjunct in pediatric cardio pulmonary resuscitation training for nursing students that help in reducing their time, and effort.

4. Similar studies should replicate the current study with a larger sample size at several universities in order to provide stronger evidence.

\section{References:}

\section{Lund-Kordahl I, Olasveengen TM,} Lorem T, Samdal M, Wik L, Sunde K. Improving outcome after out-ofhospital cardiac arrest by strengthening weak links of the local Chain of Survival. quality of advanced life support and post-resuscitation care. Resuscitation 2010;81: 422-426.

\section{Allan HT, Smith PA, and M.} Lorentzon M. "Leadership for learning: A literature study of 
leadership for learning in clinical practice." Journal of Nursing Management 2008; 16(5). 545- 555.

\section{Hughes TC, Jiwaji Z, Lally K, Lloyd-} Lavery A, Lota A, Dale A. Advanced Cardiac Resuscitation Evaluation (ACRE). A randomized single-blind controlled trial of peer-led vs. expertled advanced resuscitation training. Scandinavian Journal of Trauma Resuscitation and Emergency Medicine 2010;18(3):1-6 Available from: http://www.ncbi.nlm.nih.gov/pubmed/.

4. Evans DJ, Cuffe T. Near-peer teaching in anatomy. An approach for deeper learning. Anatomy Science Education 2009; 2:227-33.

5. Neville AJ. "Problem-based learning and medical education forty years on a review of its effects on knowledge and clinical performance." Medical Principles and Practice 2008; 18( 1):19.

\section{Kurtz CP, Lemley CS, Alverson EM.}

The master student presenter: peer teaching in the simulation laboratory. Journal of Nursing Education Perspectives 2010; 31(1): $38-40$. Available from: http://www.ncbi.nlm.nih.gov.
7. Joanne S, Zara B. The Peer Active Learning Approach for Clinical Education: A Pilot Study. Journal of Theory Construction \& Testing 2009; 13(2): 51 Available from: http://connection.ebscohost.com/.

8. Bandura A. Self-efficacy: Toward a unifying theory of behavioral change. Psychological Review 1977; 84: 191215. Available from: http://www.nataej.org/. PMid:847061 http://dx.doi.org/10.1037/0033295X.84.2.191.

9. Priharjo R, Hoy G. Use of peer teaching to enhance student and patient education. Journal of Nursing Standard 2011; 25(20): 40-43. Available from: http://nursingstandard.rcnpublishing.co. uk/.

10. Mynard J, Almarzouqi I. Investigating peer tutoring. ELT Journal 2006; 60(1): 13-22. Available from: http://eltj.oxfordj ournals.org/. http://dx.doi.org/ 10.1093/elt/cci077.

11. Gregory A, Walker I, Mclaughlin K, Peets AD. Both Preparing to Teach and Teaching Positively Impact Learning Outcomes for Peer Teachers. Journal of Medical Teacher 2011; 33(8): 417-422. 
Available from: http://www.ncbi. nlm. nih.gov/pubmed/. PMid: 21774637 http://dx. doi.org/ 10.3109/0142159X .2011 .586747

12. Lemon JB, Daigle SC. Neonatal resuscitation simulation. Nursing for Women Health, Apr/May 2010;14:143-4.

13. Smeltzer sc. and Bare BG. Text book of medical surgical nursing, $9^{\text {th }}$ ed. Philadelphia: published by Lippincott William \& Wilkins Co., 2011; 676-677.

14. Weyrich P, Celebi N, Schrauth M., Moltner A, Lammerding-Koppel M., \&Nikendei, C. Peer-assisted versus faculty staff-led skills laboratory training.A randomized controlled trial. Medical Education 2009; 43(2), 113-120.

15. McKenna L, French J. A step ahead: Teaching undergraduate students to be peer teachers. Nurse Education in Practice 2011; (2): 141-145.PMid:21051284 http://dx.doi.org/10.1016/j.nepr.20 10.10.003.

16. Secomb.J "A systematic review of peer teaching and learning in clinical education." Journal of Clinical Nursing 2008; 17(6) 703716.
17. Chojecki P, Lamarre J, Buck M, St-Sauveur I, Eldaoud N, Purden M. Perceptions of a peer learning approach to pediatric clinical education. International Journal Nursing Education Scholarship 2010; 7:1548-923.

18. Shipman D, and Hooten J. "Without enough nurse educators there will be a continual decline in RNs and the quality of nursing care: contending with the faculty shortage". Nurse Education Today 2008; 28 (5):521-523.

19. Parajulee s. and Selvaraj V. Knowledge of nurses towards CPR in a tertiary care teaching hospital in nepal. journal of clinical and diagnostic research 2011; 5(8) : 1585-1588.

20. Wolters \& Kluwer. Skill Checklists for Taylor's Clinical Nursing Skills. A Nursing Process Approach Health. $3^{\text {rd }}$ ed. Philadelphia: Lippincott Williams \& Wilkins 2011; 1367-73.

21. Iwasiw C L, Goldenberg D. Peer Teaching Among Nursing Students in The Clinical Area: Effects on Student Learning. Journal Advanced Nursing1993;18(4): 65968. Available at 
http://dx.doi.org/10.1046/j.1365-

2648.1993.18040659.x.

22. Yuan H, Williams BA, and L. Fan

L. "A systematic review of selected evidence on developing nursing students' critical thinking through problem-based learning". Nurse Education Today 2008; 28 (6) :657-663.

23. Cho GC, Sohn YD, Kang KH, Lee WW, Lim KS, Kim W. The effect of basic life support education on laypersons willingness in performing bystander hands only cardiopulmonary resuscitation. Resuscitations 2010;81: 691-694.

24. Fujiwara T, Nishimura M, Honda $R$, Nishiyama $T$, Nomoto $M$, Kobayashi N, and Ikeda $M$. Comparison of peer-led versus professional-led training in basic life support for medical students. Advances in medical education and practice 2011; 2 187-191.

25. Burgess A, Nestel D. Facilitating the development of professional identity through peer assisted learning in medical education. Advanced Medicine Education Practice 2014; 5: 403-406.

26. Stone R, Cooper S, and Cant R. The value of peer learning in undergraduate nursing education: A systematic review. Hindawi publishing corporation. ISRN Nursing. Article ID 930901 2013; Available at http://dx.doi.org/10.1155/2013/930 $\underline{901 .}$

27. Choi HS, Lee DH, Kim CW, Kim SS, and Oh JH. Peer-assisted learning to train high-school students to perform basic life support. World journal of emergency medicine2015; 6(3) 186-190.

28. Graziano SC. Randomized surgical training for medical students: resident versus peer-led teaching. American Journal of Obstetric and Gynecology2011; 204(6): 542-544.

\section{Schauseil-Zipf U, Karay Y, Ehrlich}

R, Knoop K, Michalk D. Peer Teaching in Paediatrics - Medical Students as Learners and Teachers on a Paediatric Course. GMS Zeitschrift fur Medizinische Ausbildung Journal 2010; 27(5): 116

Available from: http://www.ncbi.nlm.nih.gov/.

\section{Christiansen, B., Bjork IT, Havnes} A, and E. Hessevaagbakke E. Developing supervision skills through peer learning partnership. 
Nurse education in practice 2011; 11(2): 104-108. Available from: http://www.ncbi.nlm.nih.gov/pubm ed/21168367. PMid:21168367 http://dx.doi.org/10.1016/j.nepr.20 10.11.007.

31. Williams B, Wallia j, and Mckenna

L. How is peer-teaching perceived by first year paramedic students? result from three years. Journal of nursing education and practice 2014; 4(11) 8-14.

32. Hughes TC, Jiwaji Z, Lally K, et al. Advanced Cardiac Resuscitation Evaluation: a randomized singleblind controlled trial of peer-led versus expert-led advanced resuscitation training. Scand Journal Trauma Resuscitation Emergency Medicine 2010;18-3.

\section{Daley LK, Menke E, Kirkpatrick} B, and Sheets D. "Partners in practice: Awin-win model for clinical education". Journal of Nursing Education 2008; 47 (1) 3032.

34. Harmer, B. M., Huffman, J., \& Johnson, B. Clinical peer mentoring. Nurse Educator 2011, 36(5), 197-202.
35. Rush S, Firth T, Burke L, MarksMaran D. Implementation and evaluation of peer assessment of clinical skills for first year student nurses. Journal of Nurse Education and Practice 2012; 12(4): 219226. Available from: http://www.ncbi.nlm .nih.gov/ .

36. Brannagan KB, Dellinger $A$, Thomas J, Mitchell D, and Lewis-Trabeaux S. Impact of peer teaching on nursing students: Perceptions of learning environment, self-efficacy, and knowledge. Nurse Education Today 2012; 33(11):1440-1447.

37. Bensfield L, Solari-Twadell PA, and Sommer S. The use of peer leadership to teach fundamental nursing skills". Nurse Educator 2008; 33(4) 155-158.

38. Christiansen A, Bell A. Peer learning partnerships: exploring the experience of pre-registration nursing students. Journal of Clinical Nursing 2010; 19(5-6): 803-810. Available at http://dx.doi.org/10.1111/j.13652702.2009.02981.x. 